\title{
The reasons older immigrants in the United States of America report for returning to Mexico
}

\author{
ALMA VEGA* and KAREN HIRSCHMAN $\dagger$
}

\begin{abstract}
Mexicans are the largest immigrant group in the United States of America (USA) and are ageing rapidly. Few studies investigate whether older immigrants return to Mexico for different reasons than younger immigrants. Using the Mexican Health and Aging Study $\left(\mathrm{N}=95^{2}\right)$, we examine whether Mexican immigrants in the USA who returned to Mexico at age $5^{\mathrm{o}}$ and older report different reasons for returning than those who returned at younger ages. Few immigrants (regardless of age) returned for economic reasons. The most commonly reported reason for returning for both groups was missing family. However, the odds of selecting missing family over illness as their main reason for returning were lower for older immigrants than younger immigrants after controlling for the duration of their stay in the USA and other socio-demographic factors (odds ratio $(\mathrm{OR})=0.27 ; 95 \%$ confidence interval $(\mathrm{CI})=0.11,0.68)$. Results indicate that older immigrants were just as likely to report returning due to economic reasons and migration problems as they were to report returning because of illness $(\mathrm{OR}=0.57,95 \% \mathrm{CI}=0.15,2.21 ; \mathrm{OR}=0.41,95 \%$ $\mathrm{CI}=0.12,1.43)$. While existing research shows that older immigrants in the USA typically experience fewer migration problems and are often more economically stable than younger immigrants, our research suggests this may be entirely due to the duration of their stay in the USA.
\end{abstract}

KEY WORDS - migration, Hispanics, international retirement migration.

\section{Background}

Mexicans are the largest immigrant group in the United States of America (USA) (29.3\%) (Grieco et al. 2012) and are ageing rapidly. Between 1990 and 2011 , the proportion of Mexican immigrants in the USA aged 5 o years and older increased from 14 to 23 per cent (Gonzalez-Barrera and Lopez 2013). The presence of older Mexican immigrants in the USA affects

* Kaiser Permanente, Pasadena, California, USA.

$\dagger$ University of Pennsylvania School of Nursing, Philadelphia, Pennsylvania. 
consumption of public programmes (Smith and Edmonston 1997), healthcare expenditures (Choi 2015) and household finances, as research shows that older Mexican immigrants are often dependent on their children for lodging (Angel et al. 1999). Older immigrants also provide large amounts of child care that potentially enable other household members to remain in the labour force (Vega 2016). While less than 5 per cent of Mexican immigrants aged $5^{\circ}$ years and older returned to Mexico during the latter half of the 1990 (Vega and Brazil 2015), they represent a growing share of the Mexican immigrant population and, thus, the absolute number of those who return to Mexico may increase in years to come.

The implications of their migration patterns likely depend heavily on the characteristics of older immigrants who return to Mexico and their reasons for returning. While most Mexican immigrants report returning to Mexico because they missed family (Gonzalez-Barrera 2015), to the authors' knowledge there are no studies that examine age differences in this respect. Existing theories on international migration focus heavily on employment considerations (Massey et al. 1993) and do not make allowances for changing priorities over the lifecourse. This is the case despite the fact that Mexicans in the USA are ageing rapidly (Gonzalez-Barrera and Lopez 2013). Dowell Myers coined the term 'Peter Pan fallacy' to describe the misguided assumption that the circumstances, preferences and priorities of immigrants do not change throughout the duration of their stay in the USA (Myers 2007). The present study guards against perpetuating this misguided belief by taking into consideration age differences in relation to the reason for returning to Mexico.

Jasso et al. (2004: 242) hypothesise that for older immigrants, health weighs heavier on the decision to return than economic considerations such as employment: '[L]abor market considerations are less important for older migrants who may have either short or no remaining tenure in the labor market ... [T] he better health care available in the United States may be of far greater concern'. The quote refers to employment but for older adults, economic considerations may also include factors related to retirement such as migrating to a location with greater retirement amenities where they can enjoy a greater quality of life (Litwak and Longino 1987). For the purposes of the present study, however, we do not treat amenties as an economic consideration but as a separate retirementrelated issue similar to Litwak and Longino (1987). This allows us to explore the ways in which older immigrants differ from younger immigrants and thereby challenge the long-standing focus on employment in the immigration literature (e.g. Massey et al. 1993).

Most studies that look at age differences in return migration examine the characteristics associated with return migration (e.g. Massey 1987; Van 


\section{Alma Vega and Karan Hirschman}

Hook et al. 2006), most notably health (e.g. Arenas et al. 2015; Palloni and Arias 2004; Ullmann, Goldman and Massey 2011), but do not examine the reasons immigrants report for returning to their home countries. Such an omission can mask the sense of urgency associated with return migration. For example, immigrants who return to Mexico to use health-care services because they do not have access to US health-care services have a specific medical purpose for returning compared to immigrants who return to Mexico to visit family and happen to use health-care services while on vacation in Mexico. Moreover, simply observing the health status of return migrants does not indicate the country in which they receive health care. One group of older Canadian immigrants who spent the greater part of the year in Florida, for example, received most of their health care in Canada (Marshall 1989). If, on the other hand, immigrants report returning specifically due to health-related reasons, this may be a better indication of where they plan to be being treated.

The literature suggests Mexico's health-care system may be a viable alternative to US health care for former immigrants to the USA who returned to Mexico. Research shows that the implementation of Mexico's Seguro Popular social insurance health-care programme in 2003 may have decreased the proportion of immigrants who return to Mexico from the USA who are uninsured once in Mexico (Wassink 2016). Even when they are ineligible for need-based care, former US immigrants who returned to Mexico sometimes have the means to pay for Mexican health care. One group of former US immigrants in Mexico did not have the required work histories to participate in Mexico's public health-care system but, unlike Mexicans who had never been to the USA, were able to pay out-ofpocket to participate in these programmes (Salinas 2008). More recently, as part of Mexico's health-care reform, Mexican immigrants in the USA are able to enroll in Seguro Popular in case they return to Mexico in the future (Hawley 2011).

Existing studies that are based on self-reports examine temporary healthrelated return migration but do not examine permanent moves. Wallace, Mendez-Luck and Castañeda (2009) found that a non-trivial $5^{-6}$ per cent of Mexican immigrants in California travelled to their home country for health care in the previous year compared to less than 1 per cent of US-born non-Latino Whites. This number was 10 per cent in one nationally representative study of Hispanic immigrants (Torres and Waldinger 2015). The immigrants in these studies travelled to their home countries specifically to receive health care and re-entered the USA shortly thereafter. Similarly, in one small qualitative study, Mexican immigrants returned to Mexico to visit family but took advantage of their time in Mexico to use Mexican health-care services which they reported as being of better 
quality (Bergmark, Barr and Garcia 2010). There is no available literature that indicates the extent to which Mexican immigrants return to Mexico on a long-term basis for health-related reasons.

Despite their greater need for care compared to younger immigrants, older Mexican immigrants need not necessarily move for health-related reasons. Although not specific to older adults, existing theories of international migration underline economic motivations such as employment (e.g. Morawska 1990; Piore 1979; Sassen 1991; Sjaastad 1962; Stark and Bloom 1985). Older Mexican immigrants encounter numerous economic obstacles that may prompt them to return to Mexico for economic reasons similar to their younger counterparts who migrate between Mexico and the USA for such reasons (Durand et al. 1996; GonzalezBarrera 2015; Massey et al. 1993). In their pre-retirement years, older Hispanics experience higher unemployment rates in the USA than nonHispanic whites (Flippen and Tienda 2000) and at retirement age, sometimes lack sufficient work credits with which to receive social security benefits (Blanco et al. 2015). In the face of these economic challenges, immigrants may emigrate from the USA to avail themselves of Mexico's lower cost of living. Aguila and Zissimopoulos (2008) found that males in Mexico aged $5^{\circ}$ years and older who spent at least one year in the USA had a median monthly household income of only US \$30.30. While US immigrants who returned to Mexico are at the higher end of the Mexican wealth distribution than Mexicans who never travelled to the USA (Wong, Espinoza and Palloni 2007), the mean household net worth (US \$4,00o in 2003) for former US immigrants is far below US standards (Aguila and Zissimopoulos 2008). Thus, although they are more likely to be in poorer health than younger immigrants (Jasso et al. 2004), older immigrants may be just as likely to base their migration decisions on economic reasons given their relatively low socio-economic status in the USA.

The literature also points to the important role of family in the migration decisions of older immigrants. Older Italian and Spanish immigrants in Switzerland ranked the proximity of children as the most important factor in deciding whether to return to their home country (Bolzman 2013). The quality of health services was a distant second factor. Older British immigrants in Australia seriously considered returning to Britain to care for young grandchildren (Percival 2013). Others considered returning to reunite with siblings (Percival 2013). Although older adults themselves, some British immigrants in Australia returned to their home countries to care for elderly parents (Percival 2013). As Percival (2013: 121) notes: 'The presence of family in the home country, and an abiding bond with them, can exert a strong attraction for people in or approaching older age'. Given Mexican immigrants' strong ties to family living abroad 
(Roberts, Frank and Lozano-Ascencio 1999), it is possible that family supersedes health and economic factors in deciding whether to return to Mexico.

In this way, the decision to return to Mexico can be thought of as a mosaic of competing priorities in which certain factors take up more space on the canvas. Family, health, and economic and other factors may all be important to immigrants as they decide whether to return to Mexico but one of these factors may create the tipping point at which they commit to the action of return migration.

Understanding the relative importance of these factors is critical to projecting future trends in return migration as the population continues to age (Federal Interagency Forum on Aging-related Statistics 2010). If, for example, older immigrants return to their home countries due to illness, it is feasible to expect savings in US health-care costs. These immigrants presumably receive in Mexico the services they would have received in the USA. On the other hand, if older immigrants return to reunite with their family, savings in health-care costs may be much lower since they may not be as prone to consume health-care services had they stayed in the USA. If immigrants return to Mexico for economic reasons such as an inability to meet the cost of living in the USA, it is possible that those who rely more heavily on public programmes or those with greater unemployment levels would no longer be in the USA, possibly transferring the responsibility of providing social support for this population to Mexico.

Aside from the economic implications of their migration patterns, their reasons for returning to Mexico can shed light on the experience of ageing for immigrants in the USA. Mexican immigrants face numerous social barriers to advancing in the USA that may prompt them to return to Mexico during later life. Immigrants tend to live in disadvantaged communities (Do et al. 2007) with limited educational opportunities (Pong and Hao 2007). Immigrants also face linguistic barriers to receiving quality health care (Timmins 2002), experience discrimination and feelings of 'otherness' (Viruell-Fuentes 2007), are more likely to leave the workforce involuntarily than other groups (Flippen and Tienda 2000) and work in more injury-prone jobs that put their health at risk (Orrenius and Zavodny 2009). Recent immigrants, namely those who have been in the USA for less than five years, face the additional disadvantage of not qualifying for federally funded Medicaid and other means-tested programmes (Simpson 1986). It is possible that Mexican immigrants return to Mexico for these reasons but are unobserved in US databases. While most older immigrants in the USA own a home (Myers and Lee 1998), are English-language proficient (Ruggles et al. 2015) and are citizens of the USA (US Census Bureau 2011), these estimates do not include those who may have returned to their home countries because they fared poorly on these 
outcomes. Knowing the reasons why immigrants return to Mexico, and whether such reasons differ across the different ages upon return, can inform whether return migrants are negatively selected on these outcomes due to the social and economic barriers they face in the USA.

\section{Conceptual framework}

We use a lifecourse perspective to examine the propensity for the largest immigrant group in the USA, namely Mexican immigrants (Grieco et al. 2012), to return to Mexico due to health-related reasons. Unlike existing theories of international migration which focus on employment factors that are common during working age (Massey et al. 1993), lifecourse theory posits that social roles change across the age spectrum (Elder 1975). As a result, the rationale for migrating varies across the lifecourse (Kley 2011 ; Lee 1966).

According to Elder (1994), lifecourse theory consists of four main tenets. The first tenet, timing of lives, encapsulates changing social roles across age. Employment may hold greater sway for an immigrant with a newly formed household while health may be more important for an older widow seeking assistance. Duration of stay in the USA also reflects the timing of lives in that it is associated with the location of immediate family (Lindstrom and Giorguli-Saucedo 2007), employment (Akresh 2008; Chiswick, Cohen and Zach 1997) and likely other factors with a bearing on migration decisions. The second tenet, the interplay of human lives and historical times, maintains that social roles are interwoven into historical context. The ability of individuals to migrate, whether for employment, to reunite with family or for health, is affected by prevailing immigration laws and other features of historical time. For example, those aged $6_{5}$ years and older when the Immigration Reform and Control Act passed were exempted from proving minimal knowledge of English and American history (Simpson 1986) and more easily obtained US legal status. Upon obtaining US legal status, these immigrants became eligible for Medicare and had less incentive to return to Mexico due to illness to seek health care (although it is possible they returned for other health-related reasons such as the need for a caregiver). The third tenet, linked lives, describes the central role human relationships play in determining behaviour over the lifecourse. The decision to migrate is shaped by family considerations, whether they be providing economically for family (Massey et al. 1993), directly caring for family (Conway, Potter and St Bernard 2013) or missing family (GonzalezBarrera 2015). Finally, the tenet of human agency highlights constraints and facilitators across the lifespan. Factors such as income, citizenship status and other demographic characteristics influence an immigrant's ability to return to the home country for health-related reasons. 
Using a lifecourse framework, the goal of this study is to explore which tenets explain the decision to return to Mexico and whether these tenets differ across age. In this way, this study challenges the prevailing focus on economic motivations in determining international migration and considers whether respondents' age upon return influences this decision. This work departs from previous efforts by examining the specific reasons immigrants reported for returning to Mexico rather than the association between the particular characteristics of immigrants who return to Mexico and the act of returning to Mexico.

\section{Methods}

\section{Data}

We employ data from the Mexican Health and Aging Study (MHAS). The MHAS is a nationally representative sample of the $5^{\mathrm{O}}$ and older population in Mexico that over-samples regions in which, historically, a large number of Mexicans have left to migrate to the USA. The first wave, fielded in 2001, contains 15,186 completed interviews and had a response rate of 91.8 per cent. Respondents were reinterviewed in 2003, along with 125 new spouses (93.3\% response rate). In $2012,14,283$ of the original respondents were reinterviewed, along with 385 new spouses and 6,259 new respondents (88.1\% response rate) (Wong, Michaels-Obregon and Palloni 2015). Although the present study uses data from the 2012 wave, responses were used from previous waves when appropriate. For example, respondents who did not travel to the USA between 2003 and 2012 were not asked about their experiences in the USA in the 2012 wave. In these cases, responses from the 2001 and 2003 waves were used. Since the analysis is focused on one year of data, data are cross-sectional. Nonetheless, it was possible to use a lifecourse framework since respondents are asked retrospectively about their experiences in the USA. Examining those aged $5^{\circ}$ and older provides the advantage of eliminating younger immigrants from the analysis who might still be at risk of returning to Mexico at working age. Older immigrants are not likely to re-enter the USA after returning to Mexico. Less than 5 per cent of former US immigrant males in Mexico re-entered the USA within a five-year period (Vega and Brazil 2015). As such, this analysis is likely to capture immigrants who are not planning to re-enter the USA.

\section{Sample}

Sampled individuals and spouses are included in the sample. Of the 1,269 former US immigrants aged $5^{\mathrm{o}}$ and older in the sample, a non-trivial 11.3 
per cent $(\mathrm{N}=143)$ of proxies were dropped from the sample since they were not asked the reason the respondent last returned from the USA. To determine how excluding this group might bias results, we conducted a logistic regression in which the dependent variable was having a proxy interview (yes/no) and the independent variables were age, number of living children, citizenship status, education and sex (see Table A in the online supplementary material). This analysis included the 1,126 former US immigrants aged $5^{\circ}$ years and older who were directly interviewed and 143 proxy respondents, totalling 1,243. Results suggest that respondents with proxy interviews were more likely to be citizens or legal permanent residents of the USA (analysis not shown). We discuss the implications of this difference in the Discussion section.

Of the 1,071 non-proxy respondents with complete information for the dependent variable, namely the reason for last returning from the USA, $137(12.8 \%)$ were missing information on their migration experience due to questionnaire skip patterns. In 2001, these 137 respondents reported not having ever been to the USA and in 2003, reported having been to the USA but not within the past two years. This discrepancy is not surprising since older adults are more likely to have deficits in episodic memory and have more trouble remembering when they experienced an event and other details. These memory lapses often affect their responses on surveys (Craik 1999). For example, close to a third of respondents in the Health and Retirement Study did not recall the amount they owned in financial assets (Smith 1995). Respondents in the current study who experienced this memory lapse were skipped out of series of questions regarding their migration experience, including the age at which they last returned from the USA and whether they were citizens or legal permanent residents of the USA. However, most of these respondents $(\mathrm{N}=78$, $56.9 \%)$ worked at their current job long enough to have returned before the age of $5^{\circ}$ from the USA. For example, a 6o-year-old respondent who had been at her current job for 20 years could not have returned from the USA after age 40 . Applying this single imputation produced $95^{2} \mathrm{com}-$ plete cases. Unfortunately, we could not use a similar method to replace missing values for US citizenship/legal permanent residence $\left(\mathrm{N}=95^{2}\right.$ cases).

Of the $95^{2}$ cases, $89(9.3 \%)$ were missing information regarding their citizenship status. Instead of excluding these cases, we use multiple imputation (MI) to replace most of these missing values. Broadly, MI replaces missing data with the average of multiple values predicted from complete data (Rubin 1987). The dependent variable in the multiple imputation model equals 1 if the respondent is a US citizen or legal permanent resident. The independent variables are all those listed in Table 1 as well as 
the reason the respondent last returned from the USA (see Table B in the online supplementary material). The MI procedure imputed 72 of the 89 cases $(80.9 \%)$ who did not report whether they were US citizens or legal permanent residents. We assess the model used for the imputation procedure by calculating the area under the Receiver Operating Characteristics (ROC) curve. An ROC curve depicts a model's ability to predict accurately when cases experience an event and when they do not experience an event (Hosmer, Lemeshow and Sturdivant 2013). The area under the ROC for the imputation model was 85 per cent which is considered excellent predictive ability (Hosmer, Lemeshow and Sturdivant 2013). As another check of the imputation model, we compare the proportion of complete cases who were US citizens/legal permanent residents to those predicted to be US citizens/legal permanent residents using our imputation model. These two numbers were within two percentage points of each other (16.1 and $\mathbf{1 7 . 9} \%$, respectively; analysis not shown). We did not impute missing values for other variables with missing values since the models considered for the imputation did not perform well on the aforementioned two measures. For this reason, only 72 of the 89 missing values for citizenship status could be imputed given missing values for other variables.

\section{Dependent variable}

The dependent variable is the reason the respondent reported for having last returned from the USA. There were eight response options to the question, 'Think about the last time you were in the USA. Why did you come back to Mexico?': (a) 'You were ill', (b) 'You missed your family', (c) 'It was difficult to remain in the USA', (d) 'It was too expensive to remain in the USA', (e) 'Insufficient earnings', (f) 'Problems regarding migration', (g) 'Family problems in Mexico' and (h) 'Other'. The 'other' category is a separate response option chosen by respondents if they felt the previous categories did not capture their reasons for returning. As such, it was not possible to extract more information from this category. To increase cell sizes, the fourth and fifth categories ('It was too expensive to remain in the USA' and 'Insufficient earnings') were combined to represent having returned for economic reasons, resulting in seven possible reasons for returning. Respondents could list more than one reason but, as described below, most only reported one. Results show the proportion of respondents who reported returning for each of the seven reasons as well as the distribution of the main reason for returning. As will be discussed, in regression modelling, the dependent variable is the main reason the respondent returned to Mexico. Thus, response categories are mutually exclusive for this variable in the model. 
TA в LE 1. Demographic characteristics of Mexicans in Mexico aged 50 years and older who at some point returned from the USA

\begin{tabular}{|c|c|c|c|}
\hline & \multirow[b]{2}{*}{ Total } & \multicolumn{2}{|c|}{ Age returned } \\
\hline & & $<50$ & $5^{\circ}$ and older \\
\hline Returned at age $5^{0+}(\%)$ & 29.6 & & \\
\hline \multicolumn{4}{|l|}{ Lived in USA $(\%)$ : } \\
\hline $10+$ years & 20.7 & $15.2 * * *$ & $33 \cdot 9$ \\
\hline Missing & - & - & - \\
\hline \multicolumn{4}{|l|}{ Current age: } \\
\hline Mean (SD) & $62.6(9.9)$ & $61.0^{* * *}(9.6)$ & $66.3(9.6)$ \\
\hline Range & $5^{\mathrm{o}-9^{6}}$ & $5^{\mathrm{o}-96}$ & $5^{1-93}$ \\
\hline \multicolumn{4}{|l|}{ Married (\%): } \\
\hline Married last time returned from USA & 84.5 & $81.5^{* * *}$ & 91.6 \\
\hline Missing & 2.3 & 1.8 & 3.8 \\
\hline \multicolumn{4}{|l|}{ Number of living children: } \\
\hline Mean (SD) & $4.7(3.1)$ & $4.5(2.9)$ & $5.2(3.5)$ \\
\hline Range & $0-21$ & $0-19$ & $0-21$ \\
\hline \multicolumn{4}{|l|}{ Citizenship status (\%): } \\
\hline $\begin{array}{l}\text { US citizen/legal permanent } \\
\text { resident-imputed }\end{array}$ & 16.4 & $10.6^{* * *}$ & 30.3 \\
\hline Neither & 82.1 & $87 \cdot 5$ & 69.1 \\
\hline Missing & 1.5 & 1.9 & 0.5 \\
\hline Completed elementary school (\%) & 84.0 & $89 \cdot 4^{* * *}$ & 71.0 \\
\hline Male $(\%)$ & 82.7 & 84.1 & $79 \cdot 3$ \\
\hline Unweighted N & $95^{2}$ & 631 & $3^{21}$ \\
\hline
\end{tabular}

Notes: USA: United States of America. SD: standard deviation. Estimates weighted by Mexican Health and Aging Study-provided sampling weights. -: fewer than five observations.

Source. Authors' calculations using the 2012 Mexican Health and Aging Study.

Significance level: $* * * p<0.001$ (Rao-Scott chi-squared tests for categorical variables using non-missing values and one-way analysis of variance tests for continuous variables using non-missing values).

\section{Independent variables}

The independent variable of interest is whether respondents were aged $5^{\circ}$ years and older when they last returned from the USA. We use this cut-off instead of the normal retirement age, $6_{5}$, since several diseases are often diagnosed after age $5^{\mathrm{O}}$ and before age 65 (Centers for Disease Control and Prevention 2013; Franklin et al. 2005; Ries et al. 2006), possibly affecting the reason for returning.

Based on the four tenets of the lifecourse theory, eight variables are included in the model. The indicator for whether the immigrant last returned at age $5^{\circ}$ and older and the duration of their stay in the USA 
are included in the model to account for the timing of lives. In line with other studies (e.g. Ku 2009; LaLonde and Topel 1991), short-term migration is characterised by spending less than ten years in the USA. To account for the second tenet in the conceptual framework, interplay of human lives and historical time, the regression model controls for the respondents' age at the time of the survey. The model considers the tenet of linked lives by controlling for whether respondents were married when they last returned from the USA and the number of their living children. Several variables in the model represent human agency: gender, education and citizenship. Based on the literature, there are marked differences in the reasons why males and females migrate (Cerrutti and Massey 2001; Kanaiaupuni 200o). Therefore, gender is included in the model. Education was included since the more educated may have the social capital with which to navigate relocation during later life. Citizenship status is included since a higher proportion of former US immigrant males in Mexico who are US citizens or legal permanent residents return to Mexico at retirement age than those who do not have US legal status (Aguila and Zissimopoulos 2008).

It should be noted that the MHAS does not include employment and income characteristics at the time that immigrants last returned from the USA, only during their longest stay in the USA. However, as previously noted, the duration of immigrants' stay in the USA is associated with numerous characteristics such as employment status (Chiswick, Cohen and Zach 1997), English-language ability (Myers, Gao and Emeka 20o9) and other factors that are tied to immigrants' socio-economic context when they last returned. Although the variable for citizenship in the data-set reflects their status in the survey year, it is unlikely that immigrants obtained citizenship status after last returning from the USA. This is because legal permanent resident status can be revoked by the US government if an individual spends greater than one year outside the USA (US Citizenship and Immigration Services 2016).

\section{Statistical analysis}

Stata 14 (StataCorp, College Station, Texas) was used to conduct all analyses. Descriptive statistics were completed to compare the two groups, namely those who returned to Mexico before age $5^{\circ}$ and those who returned at age $5^{\circ}$ years and older. Bivariate analyses were performed on the aforementioned eight variables that reflect the four tenets of the lifecourse framework (Table 1). For each of the seven possible reasons for having last returned from the USA, the association between listing this reason and whether or not the respondent last returned from the USA at 
T A B L E 2. Reasons reported for having last returned from the USA among Mexicans in Mexico aged 50 years and older who at some point returned from the USA

\begin{tabular}{|c|c|c|c|c|c|c|}
\hline & \multicolumn{3}{|c|}{ Reason for returning $^{1}$} & \multicolumn{3}{|c|}{ Main reason for returning ${ }^{2}$} \\
\hline & $\begin{array}{c}\text { Returned } \\
\text { age }<5^{\circ}\end{array}$ & $\begin{array}{l}\text { Returned } \\
\text { age } 5^{\mathrm{O}+}\end{array}$ & Total & $\begin{array}{l}\text { Returned } \\
\text { age }<5^{\circ}\end{array}$ & $\begin{array}{l}\text { Returned } \\
\text { age } 5^{0+}\end{array}$ & Total \\
\hline & \multicolumn{6}{|c|}{ Percentages } \\
\hline Illness & $4 \cdot 4$ & 8.4 & 5.6 & $3 \cdot 4$ & $9 \cdot 4$ & $5 \cdot 2$ \\
\hline Missed family & 36.3 & 26.1 & $33 \cdot 3$ & 32.2 & $25 \cdot 4$ & 30.2 \\
\hline $\begin{array}{l}\text { Difficult to be in } \\
\text { the USA }\end{array}$ & 16.5 & 12.8 & $15 \cdot 4$ & $13 \cdot 7$ & 10.0 & 12.6 \\
\hline $\begin{array}{l}\text { Economic } \\
\text { reasons }\end{array}$ & $9 \cdot 4$ & 8.9 & $9 \cdot 3$ & 6.2 & 6.9 & 6.4 \\
\hline $\begin{array}{l}\text { Migration } \\
\text { problems }\end{array}$ & $5 \cdot 9$ & 8.1 & 6.5 & 5.6 & $5 \cdot 3$ & $5 \cdot 5$ \\
\hline $\begin{array}{l}\text { Family problems } \\
\text { in Mexico }\end{array}$ & 10.6 & 6.9 & $9 \cdot 5$ & 10.0 & 6.2 & 8.9 \\
\hline Other & 25.8 & 37.0 & 29.1 & $25 \cdot 4$ & 34.6 & 28.1 \\
\hline Missing & - & - & - & $3 \cdot 4$ & 2.2 & 3.1 \\
\hline $\begin{array}{l}\text { Total number of } \\
\text { reasons listed }\end{array}$ & 1.10 & 1.10 & 1.10 & - & - & - \\
\hline Unweighted N & 631 & 321 & $95^{2}$ & 631 & 321 & $95^{2}$ \\
\hline
\end{tabular}

Notes: USA: United States of America. Estimates weighted by Mexican Health and Aging Studyprovided sampling weights. -: fewer than five observations. 1. Categories are not mutually exclusive. 2. Categories are mutually exclusive. If respondents selected more than one reason for returning, they were asked to select the main reason.

Source. Authors' calculations using the 2012 Mexican Health and Aging Study.

age $5^{\mathrm{O}}$ and older was completed using a Rao-Scott chi-squared test for weighted data (Rao and Scott 1984) (Table 2).

To assess the relative importance of each of these reasons compared to illness, a multinomial logistic regression was performed on the main reason for returning to Mexico. Multinomial logistic regression resembles traditional logistic regression but can accommodate a categorical outcome with more than two response categories (Hosmer, Lemeshow and Sturdivant 2013). The reference category, illness, was based on available literature hypothesising that older immigrants are more likely to base their migration decisions on health than younger immigrants (Jasso et al. 2004). For each of the reasons for returning, a comparison was made between immigrants who reported that reason versus immigrants who reported returning due to illness. These comparisons help explain whether age directly influences whether immigrants return for health reasons or whether this relationship is the result of other characteristics that are associated with respondents' age upon return. In this way, we 


\section{Alma Vega and Karan Hirschman}

assess the relative importance of health compared to family, and economic and other factors suggested in the literature that are important in the decision to return, while ruling out the influence of different characteristics across groups. The alternative would have been to conduct multiple logistic regressions with illness as the reference category. However, conducting separate analyses is less efficient and usually results in larger standard errors than multinomial logistic regression (Agresti 2013). Odds ratios are presented. An odds ratio greater than 1 for a certain category indicates higher odds of the event occurring compared to the reference category while an odds ratio less than 1 indicates lower odds of the event occurring. For example, an odds ratio of 0.25 for a certain category indicates 75 per cent lower odds of the event occurring compared to the reference category $(1-0.25=0.75)$. Importantly, odds ratios and their corresponding confidence intervals only illustrate differences between immigrants who chose illness as their main reason for returning and those who chose other reasons for returning. We do not compare immigrants who chose these other reasons to each other. For example, we do not compare immigrants who returned due to economic reasons to immigrants who returned due to migration problems. Thus, overlapping confidence intervals across estimates indicate that there may be a difference across groups but cannot be interpreted as a statistically significant difference (Ireland 2010). The model includes all variables deemed important based on prior literature. Since respondent spouses were also interviewed, standard errors are clustered at the household level to adjust for correlation within households. All estimates are weighted using MHAS-provided population weights which account for non-response and geographic location (Instituto Nacional de Estadística y Geografía 2013).

\section{Results}

\section{Descriptive profiles}

Table 1 shows that almost a third of former US immigrants in Mexico returned at age $5^{\circ}$ years and older $(29.6 \%)$. When disaggregated by having returned at age $5^{0}$ years and older, the descriptive profiles of both groups suggest distinct lifecourse trajectories. Those who returned at older ages had spent more time in the USA, indicating a longer exposure to US customs and culture at the time of return. Approximately 33.9 per cent of those who returned at age $5^{\mathrm{O}}$ and older had spent at least ten years in the USA compared to only 15.2 per cent of those who returned before age $5^{\mathrm{O}}(p<0.001)$. Those who returned at age $5^{\mathrm{O}}$ and older were, 
on average, five years older than those who returned before age $5^{0}(66.3$ versus 61.0 , respectively; $p<0.001$ ).

Those who returned at age $5^{\circ}$ and older also potentially had more attachments to immediate family when they last returned from the USA. Ninetytwo per cent of immigrants who returned at age $5^{\circ}$ and older were married when they last returned from the USA compared to 81.5 per cent of those who returned before age $5^{\circ}(p<0.001)$. However, older return migrants did not have more children at the time of the survey than younger return migrants (mean values equal 5.2 and 4.5 , respectively; $p \geqslant 0.05)$. A much higher proportion of older return migrants were US citizens or legal permanent residents $(30.3 \%)$ than younger return migrants $(10.6 \% ; p<0.001)$. This finding suggests that the former group could more easily return to and from Mexico. The ease with which they could enter and exit the USA due to their being US citizens or legal permanent residents may have affected their reason for returning to Mexico. For example, US citizens are unlikely to have returned due to the threat of deportation. A lower proportion of those who returned at age $5^{\text {o or older }}$ had completed elementary school compared to those who last returned before age $5^{\circ}(71.0 \%$ versus $89.4 \%$; $p<0.001)$.

\section{Reasons for returning to Mexico}

The crucial role of family for both younger and older return migrants can be seen in the data presented in Table 2. This table shows the proportion of older and younger immigrants who reported each reason for returning as well as the distribution of their main reason for returning. Close to one-third of immigrants in both groups reported missing family as the main reason for having last returned from the USA. Moreover, relatively few immigrants returned for economic reasons $\left(<5\right.$ years old: $9.4 \% ; 5^{\circ+}$ years old: $8.9 \%$ ). Although given the choice to report multiple reasons for returning to Mexico, most immigrants in both groups reported only one reason for last returning from the USA. Somewhat surprisingly, immigrants who last returned to Mexico at age $5^{\mathrm{O}}$ or older were just as likely to have listed illness as a reason for last returning to Mexico than those who returned at younger ages. While illustrative, it is necessary to account for differences across groups that may be underpinning these patterns.

\section{Multinomial logistic results}

The results of a multinomial logistic regression accounting for the four tenets of lifecourse theory are presented in Table 3. This table shows results comparing immigrants who chose a particular reason for returning 
T A B L E 3. Multinomial logistic model predicting whether former US immigrants aged 50 years and older chose economics, family problems in Mexico, migration problems, difficult to be in the USA or other reasons over illness as the main reason for last returning from the USA

\begin{tabular}{|c|c|c|c|c|c|c|}
\hline & $\begin{array}{l}\text { (1) } \\
\text { Economic } \\
\text { reasons versus } \\
\text { illness }\end{array}$ & $\begin{array}{c}\text { (2) } \\
\text { Missed } \\
\text { family versus } \\
\text { illness }\end{array}$ & $\begin{array}{c}(3) \\
\text { Family } \\
\text { problems in } \\
\text { Mexico versus } \\
\text { illness }\end{array}$ & $\begin{array}{c}\text { (4) } \\
\text { Migration } \\
\text { problems } \\
\text { versus illness }\end{array}$ & $\begin{array}{l}(5) \\
\text { Difficult } \\
\text { to be in the } \\
\text { USA versus } \\
\text { illness }\end{array}$ & $\begin{array}{c}\text { (6) } \\
\text { Other } \\
\text { versus } \\
\text { illness }\end{array}$ \\
\hline & \multicolumn{6}{|c|}{ Odds ratios (95\% confidence intervals) } \\
\hline \multicolumn{7}{|l|}{ Timing of lives: } \\
\hline Returned at age $5^{\circ}$ and older & $0.57(0.15,2.21)$ & $\begin{array}{c}0.27^{* *}(0.11 \\
0.68)\end{array}$ & $0.17^{*}(0.05,0.66)$ & $0.41(0.12,1.43)$ & $0.29^{*}(0.10,0.86)$ & $0.43(0.17,1.08)$ \\
\hline Lived in the USA for $10+$ years & $0.16^{*}(0.03,0.77)$ & $0.4^{6}(0.15,1.41)$ & $1.03(0.18,5.82)$ & $1.35(0.35,5.23)$ & $0.25^{*}(0.08,0.83)$ & $0.49\left(0.17,1.4^{8}\right)$ \\
\hline \multicolumn{7}{|c|}{ Interplay of human lives and historical time: } \\
\hline Current age (natural logarithm) & $2.03(0.01,355.90)$ & $2.57(0.06,112.70)$ & $\begin{array}{l}25.6(0.26 \\
2,546.80)\end{array}$ & $\begin{array}{l}55.2(0.85 \\
\left.3,5^{6} 3.90\right)\end{array}$ & $\begin{array}{l}25.4(0.4 \mathrm{o} \\
1,597.8 \mathrm{o})\end{array}$ & $\begin{array}{l}457 \cdot 5^{\circ * *}(9 \cdot 49 \\
\left.2,205^{6.20}\right)\end{array}$ \\
\hline \multicolumn{7}{|l|}{ Linked lives: } \\
\hline Married/in union when last returned & $0.10(0.01,1.01)$ & $0.16(0.02,1.30)$ & $0.089 *(0.01,0.81)$ & $0.08 *(0.01,0.65)$ & $0.16(0.02,1.24)$ & $0.15(0.020,1.14)$ \\
\hline Number of living children & $0.92(0.78,1.10)$ & $0.98\left(0.8_{5}, 1.13\right)$ & $1.09(0.94,1.26)$ & $0.89(0.76,1.03)$ & $0.95(0.82,1.10)$ & $0.82 * *(0.72,0.95)$ \\
\hline \multicolumn{7}{|l|}{ Human agency: } \\
\hline $\begin{array}{l}\text { US citizen/legal permanent } \\
\text { resident - imputed }\end{array}$ & $1.43(0.34,5.94)$ & $2.47(0.72,8.52)$ & $0.67(0.10,4 \cdot 32)$ & $0.07^{* *}(0.01,0.39)$ & $1.77(0.47,6.61)$ & $1.31(0.42,4.07)$ \\
\hline Completed elementary school & $1.10\left(0.27,4.5^{8}\right)$ & $0.85(0.25,2.88)$ & $3.06\left(0.6_{5}, 14.3\right)$ & $2.5^{\circ}\left(0.5^{6,11.2)}\right.$ & $1.67(0.46,6.09)$ & $1.55(0.46,5.21)$ \\
\hline Male & $10.5 *(1.20,93.10)$ & $1.35(0.32,5.62)$ & $0.64(0.14,3.06)$ & $4.61\left(0.8_{3}, 25.60\right)$ & $1.34(0.28,6.43)$ & $1.53(0.37,6.38)$ \\
\hline
\end{tabular}

Notes: $\mathrm{N}=883$. USA: United States of America. Estimates are weighted using Mexican Health and Aging Study-provided sampling weights. Every column represents a comparison of the characteristics of immigrants who returned to Mexico for that particular reason $(=1)$ compared to those who returned due to illness $(=0)$. All columns represent comparisons within the same model. Standard errors are clustered at the household level. Sixty-nine observations were excluded due to missing information for one or more independent variables.

Source: Authors' calculations using the 2012 Mexican Health and Aging Study.

Significance levels: $* p<0.05, * * p<0.01$. 
(i.e. missing family, difficult to be in the USA, economic reasons, migration problems, family problems in Mexico and 'other') compared to those who chose illness, the reference category. The columns represent comparisons within the same multinomial logistic model and not separate logistic regressions. Results can be interpreted in a similar way to odds ratios from a logistic regression. Results show that older immigrants were less likely to have chosen missing family over illness as their main reason for returning to Mexico (column 2). Specifically, the odds of having chosen missing family instead of illness as their main reason for returning were 73 per cent lower among immigrants who returned to Mexico at age $5^{\mathrm{O}}$ and older than among those who returned at younger ages $(\mathrm{OR}=0.27, p<0.01$; column 2). Thus, while missing family was the most prevalent reason reported for returning for both older and younger immigrants (Table 2), the former were still less likely to choose missing family over illness. This pattern also holds for choosing family problems in Mexico as the main reason for returning $(\mathrm{OR}=0.17, p<0.05$; column 3$)$ and choosing the difficulty of living in the USA as the main reason $(\mathrm{OR}=0.29, p<0.05$; column 5$)$. Older immigrants were less likely to have chosen these reasons over illness than younger immigrants. In contrast, older immigrants were just as likely to return due to illness as they were to return due to economic reasons $(\mathrm{OR}=0.57, p \geqslant 0.05)$ and migration problems $(\mathrm{OR}=0.41, p \geqslant 0.05)$.

\section{Discussion}

Findings in the present study indicate that relatively few former Mexicans in Mexico with a history of migration to the USA, regardless of age, report returning to Mexico due to economic reasons. The most commonly reported reason for returning to Mexico for immigrants who returned to Mexico at both younger and older ages was missing family. However, the odds of selecting missing family over illness as their main reason for returning were lower for older immigrants than younger immigrants after controlling for the duration of their stay in the USA and other socio-demographic factors. In contrast, older immigrants were just as likely to choose economic issues and migration problems instead of illness after controlling for these factors. These results have several implications.

Our results suggest changing priorities for Mexican immigrants over the timing of lives, herein captured by the duration of their stay in the USA. Despite the heavy focus on employment- and income-related migration in the return migration literature (e.g. Durand et al. 1996; Stark, Hemelstein and Yegorov 1997; Vega 2015), results show that relatively few former US immigrants returned to Mexico for these reasons. Employment and wages 
may be the primary reasons that immigrants move to the USA but family relationships may become more important after they reach their initial financial goals. One explanation for this finding may be our focus on former US immigrants in Mexico who at some point emigrated to the USA and returned rather than those who have emigrated to the USA since 2009 and returned. In a recent study by Gonzalez-Barrera (2015), former US immigrants who have emigrated to the USA since 2009 and returned to Mexico most commonly reported lack of work in the USA as their reason for returning to Mexico. The small number of immigrants who returned after 2009 in the MHAS did not allow us to examine differences between those who returned before and after the economic downturn of 2008.

Instead, findings highlight the pivotal role of family, or in lifecourse framework terminology, linked lives, in determining return migration for both age groups. Familial ties exerted the greatest influence in their decision to return for both older and younger Mexican immigrants. This result falls in line with previous research which finds that family was the most cited reason for Mexican immigrants in the USA who returned to Mexico (Gonzalez-Barrera 2015). The results of the present study suggest this is true regardless of the age at which respondents return to Mexico. It remains unclear, however, how the nature of family ties change across age. Younger return migrants were less likely to be married than older return migrants when they last returned from the USA, suggesting that younger return migrants returned due to their closeness with non-spouse family members. Other research has shown that older immigrants also maintain close ties to non-spouse family members (Conway, Potter and St Bernard 2013; Percival 2013). Older immigrants return to their home countries to reunite with siblings, grandchildren and elderly parents (Conway, Potter and St Bernard 2013; Percival 2013). Our finding may reflect strong family connections that may change across age but that do not diminish the allure of the home country.

Family was the most reported reason for returning to Mexico, even more so than economic reasons. Two-thirds fewer respondents reported returning for economic reasons than did those who reported returning because they missed family. Economic reasons might be at the forefront of immigrants' intentions as they enter the USA but the pull of family does not appear to lessen over time. Importantly, only limited inferences can be made regarding the relative importance of family versus economic reasons in the decision to return since these two categories were not compared in a regression context, only descriptively. As such, more research is needed to understand the inflection point at which the pull of family in the home country takes precedence over the original economic motivation for entering the USA. 
Our results also challenge existing typologies of the role of linked lives in migration throughout the lifecourse. In existing theories on later-life migration, family members are important in older adults' migration decisions because they provide care-giving support rather than because they miss their company (Litwak and Longino 1987; Wiseman 1980). Wiseman (1980) posits that older adults tend to move closer to family members as they become frailer in order to receive assistance. This model recognises linked lives as encouraging physical closeness to family for assistance reasons but does not account for the closer family ties within immigrant communities even across international borders (Roberts, Frank and Lozano-Ascencio 1999). The results of the present study connote strong family bonds across the lifecourse irrespective of the need for assistance. In other words, lives are linked more so by emotional closeness rather than the need for care. Litwak and Longino (1987) move closer to characterising later-life migration among older immigrants, only to the extent that they acknowledge that this group does not fall into their theory. The authors argue that native-born older adults move to seek amenities and then to seek assistance as their health begins to decline. Furthermore, Litwak and Longino (1987) acknowledge that older immigrants are likely to deviate from this pattern since they have stronger family ties and are less likely to use institutional care. The results presented herein support this assertion and highlight the need for theories of international migration specific to older adults.

Despite the importance of family for immigrants who returned to Mexico from the USA at both younger and older ages, our findings reveal differences in the motives undergirding migration depending on the age at which they returned or, in lifecourse terminology, the timing of lives. Those who returned at older ages were less likely to have chosen missing family and family problems in Mexico over illness as their main reason for returning. Therefore, even though missing family was the most important reason for returning, older immigrants were still more likely to view illness as the most imminent reason for returning. This evidence of shifting priorities across age lends credence to what Elder (1994: 6) refers to as the 'sequence of roles ... based on age'. Family may be at the forefront of decisions when immigrants arrive as working-age adults but illness gradually takes hold and is more likely to drive their decisions as they experience declining health during later life. Their greater preoccupation with health is one of the distinguishing features that sets older immigrants apart from their younger counterparts.

This finding lends support to the hypothesis of Jasso et al. (2004) regarding the importance of health in the decisions of older immigrants. As previously mentioned, the authors hypothesise that health weighs much more 
heavily for older immigrants than younger immigrants. Jasso et al. (2004) compared the importance of health to employment considerations and not family, but our results suggest the same pattern may also hold between health and family. Family was the most reported reason for returning to Mexico but illness shifts to being more important as immigrants age. Thus, even though older immigrants often travel internationally to care for grandchildren (Toro-Morn 1995; Treas 2008) and elderly parents (Percival 2013), our research suggests this tendency may diminish as they experience declining health.

On one level this is not surprising; older immigrants are more likely to be ill (Jasso et al. 2004) and, thus, have grounds for prioritising their health over family. On the other hand, poor health need not necessarily motivate immigrants to return to their countries of origin. While some studies find evidence that immigrants return to their home countries in anticipation of death (e.g. Palloni and Arias 2004), authors argue that poor health may actually motivate immigrants to stay in the USA because of its superior health-care system (Jasso et al. 2004). The results of the present study show that despite the presumed better quality of the USA health-care system, 8 per cent of older immigrants who returned to Mexico did so because of illness. Although not nearly as large as the proportion who moved for family reasons, this number can have non-negligible effects on health spending given the disproportionate amount of health spending that goes towards older adults. In 2010, adults aged 45 and older constituted 39 per cent of the US population (Jasso et al. 2004) but consumed 47 per cent of all Medicaid dollars (US Census Bureau 2012). Mexican immigrants who return to Mexico at this age for health reasons potentially diminish these expenditures, particularly in states with large immigrant populations.

One explanation for this result may be that in the absence of US health coverage, older Mexican immigrants turn to Mexico's lower-cost healthcare system as an alternative. Such a move can be thought of as an exercise of human agency whereby immigrants return to Mexico to obtain resources that they did not have access to in the USA. Reyes and Hardy (2015) found that pre-retirement Latino immigrants are more likely to lose health coverage than both native-born non-Hispanic whites as well as other immigrant groups. It is possible that uninsured immigrants return to Mexico to substitute hospital-based medical attention with informal care provided by private pharmacies, a common practice in Mexico (Wong and Palloni 2009). In this way, return migration may be a means of using human agency to overcome constraints of living in the USA during later life, namely limited health care. Future research should examine whether the number of immigrants returning to Mexico due to illness has decreased after the Affordable Care Act was passed into law in March 
2010, which provides access to lower-cost health care through the Exchange Marketplace for naturalised citizens and legal permanent residents. Another reason why illness may motivate older Mexican immigrants to return to Mexico is the absence of a care-giver in the USA. Older adults who are not living in their home countries are often separated from caregivers still living in the home country (Anderson 1991).

Interestingly, after controlling for the other tenets of lifecourse theory, older immigrants were just as likely to report returning due to economic issues and migration problems as they were to report returning due to illness. This is partially explained by the greater tendency for older return migrants to have lived in the USA for more than ten years compared to younger return migrants. In other words, for immigrants who had not been in the USA very long, the act of returning to Mexico was an act of human agency to overcome economic and migration problems in the USA. While existing research shows that older immigrants in the USA typically experience fewer deportation problems (Myers 2007) and are often more economically stable than younger immigrants (Myers 2007), our research suggests this may be entirely due to the duration of their stay in the USA. This finding informs our understanding of older immigrants' wellbeing in the USA. Our research shows that older immigrants are concerned about declining health. However, unlike native-born older adults, older recent immigrants have the added burden of establishing and maintaining legal status in the USA. Older recent immigrants must also overcome the economic difficulties often associated with having recently arrived to the USA (Angel et al. 1999). Given the growing proportion of new immigrants who are older adults (Carr and Tienda 2013), future research may show that older immigrants are just as likely to return due to illness as they are to return for economic and migration problems.

\section{Limitations}

It is important to mention noteworthy limitations of this study. First, this analysis is limited to respondents with direct interviews and does not include those with proxy interviews. An analysis of the differences between respondents with both types of interviews indicates that the latter group were more likely to be citizens or legal permanent residents of the USA. Immigrants with US legal status may be less likely to return due to declining health since they are eligible for Medicare and Medicaid. Moreover, since they presumably have more ties to the USA, they may be more likely to have family in the USA to care for them during later life. If this were the case, this would further validate the finding from this study regarding the importance of familial bonds in the migration decision. 


\section{2

Another limitation is that the data do not contain information regarding where immigrants' family resided when immigrants last returned to Mexico. Such information would illuminate possible family ties weighing on the decisions of immigrants. Nonetheless, the present analysis controls for whether the immigrant was married when he or she last returned from the USA, thereby accounting for the greater responsibility associated with forming one's own household. This study is also limited to retrospective cross-sectional data rather than panel data which follow immigrants over time. Given the difficulty of tracking movement across international borders, particularly older adults, to the authors' knowledge, this is the best available information. Yet another limitation is that adults aged 70 and older have cited health as a major incentive for moving domestically within the USA (Choi 1996) but 'younger' older immigrants are thought to move within the USA for amenities (Litwak and Longino 1987). Unfortunately, it was not possible to disaggregate older immigrants into more granular age categories due to sample size restrictions. Nonetheless, this analysis provides a general accounting of differences between older and younger immigrants which is more than is currently available for this population. Another limitation is that we only compare immigrants who chose 'illness' as their main reason for returning to those who chose reasons other than 'illness'. We do not compare immigrants who chose these other reasons to each other. Nonetheless, we explore an important relationship hypothesised in the migration literature (Jasso et al. 2004) that had not previously been examined in a quantitative context.

Finally, another limitation is the high proportion of respondents who report 'other' reasons for having last returned from the USA (29.1\%). This falls in line with prior research that report 'other' as a reason for return migration (e.g. Gonzalez-Barrera 2015; Niedomysl and Amcoff 2011), albeit not as high as the proportion in the current study. The higher proportion that reported 'other' reasons in our study may be attributable to our focus on older adults. The scant research on older immigrants compared to younger immigrants provides fewer potential reasons for returning to Mexico. This result signals the need for further inquiry into the reasons for returning to Mexico among Mexican immigrants in the USA. Qualitative work on other groups, for example, suggests that immigrants return to their home countries to assist family members abroad (Conway, Potter and St Bernard 2013), and to enjoy a better climate (Conway, Potter and St Bernard 2013) and a more active social life (Bolzman, Fibbi and Vial 2006), reasons that were not listed as separate categories in the questionnaire. Another reason hypothesised to matter in the migration decisions of older adults is the quest for greater amenities (Litwak and Longino 1987). This could not be explored in the present study and is a 
worthy future pursuit. Not knowing the reasons embedded in the 'other' category, however, does not preclude us from knowing the importance of health and missing family in the return migration decision.

\section{Conclusion}

Net migration from Mexico to the USA (entering immigrants minus exiting emigrants) is at its lowest since the 1990 (Gonzalez-Barrera 2015). Research suggests that economic factors such as landownership (Massey 1987), asset accumulation (Stark, Hemelstein and Yegorov 1997) and the availability of jobs in the USA (Gonzalez-Barrera 2015) play an important role in migration decisions. However, the present study finds that few immigrants reported returning for economic reasons. Instead, the most cited reason for returning to Mexico among those who returned at older and younger ages was missing their family. This is the case even as the former group was more likely to return due to illness. These results illuminate the reasons for decisions to return to Mexico for a growing population whose actions have major ramifications for US health-care spending, public programme usage and the dynamics within immigrant households.

Our results call into question the existing focus on economic motivations in determining return migration and highlight shifting priorities over the lifecourse of Mexican immigrants in the USA. Findings suggest that while employment may be central to the decision to migrate to the USA, social bonds carry more weight the longer immigrants remain in the USA and are more likely to drive the decision to return. Moreover, as immigrants age, return migration may serve as a vehicle through which they exert human agency in overcoming social and economic challenges in the USA. As Mexican immigrants continue to age, it is imperative that theories of international migration recognise their changing circumstances and how this might affect their decision to return.

\section{Supplementary material}

To view supplementary material for this article, please visit https://doi.org/ $10.1017 /$ So $144686 X_{17001155}$

\section{Acknowledgements}

This research was made possible by a pilot grant from the NewCourtland Center for Transitions and Health. This research is based on publicly available data, thus ethical approval was not required. 


\section{References}

Agresti, A. 2013. CategorialData Analysis. Third edition, John Wiley \& Sons, Hoboken, New Jersey.

Aguila, E. and Zissimopoulos, J. 2008. Labor Market and Immigration Behavior of Middleaged and Elderly Mexicans. Working Paper 2008-192, University of Michigan Retirement Research Center. Available online at http://www.mrrc.isr.umich. $\mathrm{edu} / \mathrm{research} /$ projects/index_research_detail.cfm?pid=UMo8-14 [Accessed 4 September 2014].

Akresh, I. R. 2008. Occupational trajectories of legal U.S. immigrants: downgrading and recovery. Population and Development Review, 34, 3, 435-5

Anderson, J. M. 1991. Immigrant women speak of chronic illness: the social construction of the devalued self. Journal of Advanced Nursing, 16, 6, 710-7.

Angel, R. J., Angel, J. L., Lee, G.-Y. and Markides, K. S. 1999. Age at migration and family dependency among older Mexican immigrants: recent evidence from the Mexican American EPESE. The Gerontologist, 39, 1, 59-65.

Arenas, E., Goldman, N., Pebley, A. R. and Teruel, G. 2015. Return migration to Mexico: does health matter? Demography, 52, 6, 1853-68.

Bergmark, R., Barr, D. and Garcia, R. 2010. Mexican immigrants in the U.S. living far from the border may return to Mexico for health services. Journal of Immigrant and Minority Health, 12, 4, 610-4.

Blanco, L., Aguila, E., Gongora, A., Weidmer, B. and Duru, O. K. 2015 . Retirement Planning Among Middle-aged and Older Hispanics. School of Public Policy Working Paper 3-2015. Available online at http://digitalcommons.pepperdine.edu/cgi/ viewcontent.cgi? article $=1053 \&$ context $=$ sppworkingpapers $[$ Accessed 23 July 2016].

Bolzman, C. 2013. Ageing immigrants and the question of return: new answers to an old dilemma? In Percival, J. (ed.), Return Migration in Later Life: International Perspectives. Policy Press, Bristol, UK, 67-88.

Bolzman, C., Fibbi, R. and Vial, M. 20o6. What to do after retirement? Elderly migrants and the question of return. Journal of Ethnic and Migration Studies, 32, $8,1359^{-} 75$.

Carr, S. and Tienda, M. 2013. Family sponsorship and late-age immigration in aging America: revised and expanded estimates of chained migration. Population Research and Policy Review, 32, 6, 825-49.

Centers for Disease Control and Prevention 2013. Distribution of Age at Diagnosis of Diabetes Among Adult Incident Cases Aged I 8-79 Years, United States, 201 I. Available online at http://www.cdc.gov/diabetes/statistics/age/fig $1 . h t m$ [Accessed 22 July 2016].

Cerrutti, M. and Massey, D.S. 2001. On the auspices of female migration from Mexico to the United States. Demography, 38, 2, 187-200.

Chiswick, B. R., Cohen, Y. and Zach, T. 1997. The labor market status of immigrants: effects of the unemployment rate at arrival and duration of residence. Industrial and Labor Relations Review, 5o, 2, 289-303.

Choi, N. G. 1996. Older persons who move: reasons and health consequences. Journal of Applied Gerontology, 15, 3, 325-44.

Choi, S. 2015. Out-of-pocket expenditures and the financial burden of healthcare among older adults: by nativity and length of residence in the United States. Journal of Gerontological Social Work, 58, 2, 149-70.

Conway, D., Potter, R. B. and St Bernard, G. 2013. Caribbean return migration in later life: family issues and transnational experiences as influential pre-retirement 
factors. In Percival, J. (ed.), Return Migration in Later Life. Policy Press, Bristol, UK, 89-112.

Craik, F. I. M. 1999. Memory, aging, and survey measurement. In Schwartz, N., Park, D. C., Knauper, B. and Sudman, S. (eds), Cognition, Aging, and Self-reports. Psychology Press, Philadelphia, 82-99.

Do, D. P., Dubowitz, T., Bird, C. E., Lurie, N., Escarce, J.J. and Finch, B. K. 2007. Neighborhood context and ethnicity differences in body mass index: a multilevel analysis using the NHANES III survey (1988-1994). Economics and Human Biology, 5, 2, 179-203.

Durand, J., Kandel, W., Parrado, E. A. and Massey, D. S. 1996. International migration and development in Mexican communities. Demography, 33, 2, 249-64.

Elder, G. H. 1975. Age differentiation and the life course. Annual Review of Sociology, $\mathbf{1}, 1,165^{-90 .}$

Elder, G. H., Jr 1994. Time, human agency, and social change: perspectives on the life course. Social Psychology Quarterly, 57, 1, 4-15.

Federal Interagency Forum on Aging-related Statistics 2010. Older Americans 2010: Key Indicators of Well-being. Available online at http://www.agingstats.gov/agingstatsdotnet/Main_Site/Data/2010_Documents/docs/OA_2010.pdf [Accessed 22 July 2016].

Flippen, C. and Tienda, M. 200o. Pathways to retirement: patterns of labor force participation and labor force exit among the pre-retirement population by race, Hispanic origin, and sex. Journals of Gerontology: Social Sciences, 55B, 1, S14-27.

Franklin, S., Pio, J. R., Wong, N. D., Larson, M. G., Leip, E. P., Vasan, R. S. and Ley, D. 2005 . Predictors of new-onset diastolic and systolic hypertension: the Framingham Heart Study. Circulation, 111, 9, $1121-27$.

Gonzalez-Barrera, A. 2015 . More Mexicans Leaving the U.S. Than Coming to the U.S.: Net Loss of I 40,000 from 2009 to 20 I4: Family Reunification Top Reason for Return. Pew Hispanic Center. Available online at http://www.pewhispanic.org/2015/11/ 19/more-mexicans-leaving-than-coming-to-the-u-s/ [Accessed 26 January 2016].

Gonzalez-Barrera, A. and Lopez, M. H. 2013. A Demographic Portrait of Mexican-origin Hispanics in the United States (Statistical Profile 2013-O4). Pew Hispanic Center. Available online at http://www.pewhispanic.org/2013/05/o1/a-demographicportrait-of-mexican-origin-hispanics-in-the-united-states/ [Accessed 17 February 2016].

Grieco, E. M., Acosta, Y. D., de la Cruz, G. P., Gambino, C., Gryn, T., Larsen, L. J., Trevelyan, E. N. and Walters, N. P. 2012. The Foreign-born Population in the United States: 20I0. American Community Survey Reports ACS-19, US Census Bureau. Available online at http://www.census.gov/prod/201 2pubs/acs-1 9.pdf [Accessed 22 July 2016].

Hawley, C. 201 1. Mexicans Find Leaving the U.S. a HardDecision. Available online at http:// usatoday3o.usatoday.com/printedition/news/20081210/mexicomigrants 10_st. art.htm [Accessed 22 June 2016].

Hosmer, D. W., Lemeshow, S., and Sturdivant, R. X. 2013. Applied Logistic Regression. Third edition, John Wiley \& Sons, New York.

Instituto Nacional de Estadística y Geografía [National Institute of Statistics and Geography] 2013. Mexican Health and Aging Study (2012): Sample Design. Available online at http://mhasweb.org/Resources/DOCUMENTS/2012/ Methodological_Document_2012\%E2\%80\%93SEC.pdf [Accessed 23July 2016].

Ireland, C. R. 2010. Experimental Statistics for Agriculture and Horticulture. CABI, Wallingford, UK.

Jasso, G., Massey, D. S., Rosenzweig, M. R. and Smith, J. P. 2004. Immigrant health: selectivity and acculturation. In Anderson, N. B., Bulatao, R. A. and Cohen, B. 
(eds), Critical Perspectives on Racial and Ethnic Differences in Health in Late Life. National Academies Press, Washington DC, 227-66.

Kanaiaupuni, S. M. 2000. Reframing the migration question: an analysis of men, women, and gender in Mexico. Social Forces, 78, 4, $1311-47$.

Kley, S. 2011. Explaining the stages of migration within a life-course framework. European Sociological Review, 27, 4, 469-86.

$\mathrm{Ku}$, L. 2009. Health insurance coverage and medical expenditures of immigrants and native-born citizens in the United States. American Journal of Public Health, 99, $7,1322-8$.

LaLonde, R.J. and Topel, R. H. 1991. Immigrants in the American labor market: quality, assimilation, and distributional effects. The American Economic Review, 81, 2, 297-302.

Lee, E. S. 1966. A theory of migration. Demography, 3, 1, 47-57.

Lindstrom, D. P. and Giorguli-Saucedo, S. 2007. The interrelationship between fertility, family maintenance, and Mexico-US migration. Demographic Research, $17,28,821-58$.

Litwak, E. and Longino, C. F. 1987. Migration patterns among the elderly: a developmental perspective. The Gerontologist, 27, 3, 266-72.

Marshall, V. W. 1989. Health care utilization of Canadian snowbirds. Journal of Aging and Health, 1, 2, $15^{\mathrm{O}-68 .}$

Massey, D. S. 1987 . Understanding Mexican migration to the United States. American Journal of Sociology, 92, 6, 1372-403.

Massey, D. S., Arango, J., Hugo, G., Kouaouci, A., Pellegrino, A. and Taylor, J. E. 1993. Theories of international migration: a review and appraisal. Population and Development Review, 19, 3, 431-66.

Morawska, E. 1990. The sociology and historiography of immigration. In YansMcLaughlin, V. (ed.), Immigration Reconsidered: History, Sociology, and Politics. Oxford University Press, New York, 187-240.

Myers, D. 2007. Immigrants and Boomers. Russell Sage Foundation, New York.

Myers, D., Gao, X. and Emeka, A. 20o9. The gradient of immigrant age-at-arrival effects on socioeconomic outcomes in the US. International Migration Review, 43, $1,205^{-29}$.

Myers, D. and Lee, S. W. 1998. Immigrant trajectories into homeownership: a temporal analysis of residential assimilation. International Migration Review, 32, 3, $593-625$.

Niedomysl, T. and Amcoff, J. 201 1. Why return migrants return: survey evidence on motives for internal return migration in Sweden. Population, Space and Place, 17, 5 , $65^{6-73}$.

Orrenius, P. M. and Zavodny, M. 2009. Do immigrants work in riskier jobs? Demography, 46, $3,535^{-} 5^{1 .}$

Palloni, A., and Arias, E. 2004. Paradox lost: explaining the Hispanic adult mortality advantage. Demography, 41, 3, 385-415.

Percival, J. 2013. 'We belong to the land': British immigrants in Australia contemplating or realising their return 'home' in later life. In Percival, J. (ed.), Return Migration in Later Life. Policy Press, Bristol, UK, $113-39$.

Piore, M.J. 1979. Birds of Passage: Migrant Labor and Industrial Societies. Cambridge University Press, Cambridge.

Pong, S. L. and Hao, L. 2007. Neighborhood and school factors in the school performance of immigrants' children. International Migration Review, 41, 1, 206-41.

Rao, J. N. K. and Scott, A.J. 1984. On chi-squared tests for multiway contingency tables with cell proportions estimated from survey data. Annals of Statistics, 12, 1, 46-6o. 
Reyes, A. M. and Hardy, M. 2015. Health insurance instability among older immigrants: region of origin disparities in coverage. Journals of Gerontology: Psychological Sciences and Social Sciences, 7oB, 2, 303-13.

Ries, L. A. G., Harkins, D., Krapcho, M., Mariotto, A., Miller, B., Feuer, E., Clegg, L., Eisner, M., Horner, M., Howlader, N., Hayat, M., Hankey, B. and Edwards, B. 2006. SEER Cancer Statistics Review: Table I-I I Median Age of Cancer Patients at Diagnosis, 2000-2003. Available online at http://seer.cancer.gov/archive/csr/ 1975_2003/results_single/sect_o1_table.11_2pgs.pdf. [Accessed 6 October $2017]$

Roberts, B. R., Frank, R. and Lozano-Ascencio, F. 1999. Transnational migrant communities and Mexican migration to the U.S. Ethnic and Racial Studies, 22, 2, $23^{8}-66$.

Rubin, D. B. 1987. Multiple Imputation for Nonresponse in Surveys. John Wiley \& Sons, New York.

Ruggles, J.S., Alexander, T., Genadek, K., Goeken, R., Schroeder, M. B. and Sobek, M. 2015. Analyze Data Online: ACS 5-Year Sample, 2010-2015: Integrated Public Use Microdata Series: Version 6.o [Machine-readable database]. University of Minnesota, Minneapolis. Available online at https://sda.usa.ipums.org/cgi-bin/ sdaweb/hsda?harcsda+us2014c [Accessed 10 June 2016].

Salinas, J. J. 2008. Tapping healthcare resource by older Mexicans with diabetes: how migration to the United States facilitates access. Journal of Cross-cultural Gerontology, 23, 3, 301-12.

Sassen, S. 1991. The Global City: New York, London, Tokyo. Princeton University Press, Princeton, New Jersey.

Simpson, A. K. 1986. S. I20o-Immigration Reform and Control Act of I986. Available online at http://thomas.loc.gov/cgi-bin/bdquery/z?do99:SNo 1200 : @@@L\&summ2=m\&TOM:/bss/dog9query.html [Accessed 27 January 2016].

Sjaastad, L. A. 1962. The costs and returns of human migration. Journal of Political Economy, 7o, 5, part 2, 80-93.

Smith, J.P. 1995. Racial and ethnic differences in wealth in the Health and Retirement Study. Journal of Human Resources, 3o, Special Issue, S1 58-83.

Smith, J. P. and Edmonston, B. 1997. The New Americans: Economic, Demographic, and Fiscal Effects of Immigration. National Academies Press, Washington DC.

Stark, O. and Bloom, D.E. 1985. The new cconomics of labor migration. The American Economic Review: Papers and Proceedings of the Ninety-seventh Annual Meeting of the American Economic Association, 75, 2, 173-8.

Stark, O., Hemelstein, C. and Yegorov, Y. 1997. Migrants' savings, purchasing power parity, and the optimal duration of migration. International Tax and Public Finance, 4, 3, 307-24.

Timmins, C. L. 2002. The impact of language barriers on the health care of Latinos in the United States: a review of the literature and guidelines for practice. Journal of Midwifery Eீ Women's Health, 47, 2, 80-96.

Toro-Morn, M. I. 1995. Gender, class, family, and migration: Puerto Rican women in Chicago. Gender and Society, 9, 6, 71 2-26.

Torres, J. M. and Waldinger, R. 2015. Civic stratification and the exclusion of undocumented immigrants from cross-border health care. Journal of Health and Social Behavior, 56, 4, 438-59.

Treas, J. 2008. Transnational older adults and their families. Family Relations, 57, 4, $468-78$.

Ullmann, S. H., Goldman, N. and Massey, D. S. 2011 . Healthier before they migrate, less healthy when they return? The health of returned migrants in Mexico. Social Science and Medicine, 73, 3, 421-8. 


\section{Alma Vega and Karan Hirschman}

US Census Bureau 2011. Current Population Survey-March 20I I Detailed Tables: Table I.I. Population by Age, Sex, Nativity, and U.S. Citizenship Status, 20 II. Available online at https://www.census.gov/data/tables/2011/demo/foreignborn/cps-2011.html [Accessed 7 October 2017].

US Census Bureau 201 2. Age and Sex Composition in the United States: 20Io. Table I. Available online at http://www.census.gov/population/age/data/201 ocomp. html [Accessed 22 July 2016].

US Citizenship and Immigration Services 2016. International Travel as a Permanent Resident. Available online at https://www.uscis.gov/green-card/after-green-cardgranted/international-travel-permanent-resident [Accessed 22 February 2016].

Van Hook, J., Zhang, W., Bean, F. D. and Passel, J. S. 2006. Foreign-born emigration: a new approach and estimates based on matched CPS files. Demography, 43, 2, 361-82.

Vega, A. 2015. The impact of Social Security on return migration among Latin American elderly in the U.S. Population Research and Policy Review, 34, 3, 307-30.

Vega, A. 2016. The time intensity of childcare provided by older immigrant women in the United States. Research on Aging. 39, 7, 823-48.

Vega, A. and Brazil, N. 2015. A multistate life table approach to understanding return and reentry migration between Mexico and the United States during later life. Demographic Research, 33, 43, $1211-40$.

Viruell-Fuentes, E. A. 2007. Beyond acculturation: immigration, discrimination, and health research among Mexicans in the United States. Social Science and Medicine, $\mathbf{6}_{5}, 7,15^{24}-35$.

Wallace, S. P., Mendez-Luck, C. and Castañeda, X. 2009. Heading south: why Mexican immigrants in California seek health services in Mexico. Medical Care, 47, 6, 662-9.

Wassink, J. T. 2016. Implications of Mexican health care reform on the health coverage of nonmigrants and returning migrants. American Journal of Public Health, 1o6, $5,848-5$ o.

Wiseman, R. F. 1980. Why older people move: theoretical issues. Research on Aging, 2 , $2,141-54$.

Wong, R., Espinoza, M. O. and Palloni, A. 2007. Adultos mayores mexicanos en contexto socioeconómico amplio: salud y envejecimiento. Salud Pública de México, 49, supplment $4, \mathrm{~S}_{43}{ }^{6-47}$.

Wong, R., Michaels-Obregon, A. and Palloni, A. 2015. Cohort profile: the Mexican Health and Aging Study (MHAS). International Journal of Epidemiology. 46, 2, epage 2.

Wong, R. and Palloni, A. 20o9. Aging in Mexico and Latin America. In Uhlenberg, P. (ed.), International Handbook of Population Aging. Volume 1, Springer, New York, $23^{1-52 .}$

Accepted 2 I September 2017 ; first published online 26 October 2017

Address for correspondence:

Alma Vega,

Kaiser Permanente,

393 East Walnut Street,

Pasadena,

CA 91188 , USA

E-mail: alma.c.vega-rivera@kp.org 